\title{
Quality at Time of Purchase of Dried Milk Products Commercially Packaged in Reduced Oxygen Atmosphere
}

\author{
M. A. Lloyd, J. Zou, H. Farnsworth, L. V. Ogden, and O. A. Pike \\ Department of Nutrition, Dietetics and Food Science, \\ Brigham Young University, S-221 ESC, Provo, UT 84602
}

\begin{abstract}
Nonfat dry milk (NDM) and powdered whey beverages are available at the retail level, packaged in No. 10 cans in a reduced oxygen atmosphere to prolong shelf life. The objective of this research was to determine the sensory and nutritional quality of these dried milk products at the time of purchase. In the 10 brands tested, wide variation existed in headspace oxygen, can seam quality, sensory quality, and vitamin A (with 6 of 10 brands entirely lacking the vitamin). Manufacturers of dried milk products packaged in cans for longterm storage need to give careful attention to can seam quality, product labeling, and vitamin fortification. Consumers would be well advised to evaluate several brands of dried milk products prior to large quantity purchases.
\end{abstract}

(Key words: long-term storage, nonfat dry milk, vitamin fortification, modified atmosphere packaging)

Abbreviation key: DV = daily value.

\section{INTRODUCTION}

The US Department of Homeland Security has recommended that US citizens store food and supplies for use in an emergency (DHS, 2003). A variety of such food products are available at the retail level, packaged in No. 10 cans with reduced oxygen atmospheres to prolong shelf life. These products are often stored for extended periods of time before being opened, and thus the quality at the time of retail sale is often unknown to the consumer. Among these dried milk products are NDM and whey powder beverages (marketed as milk substitutes). Dried milk products must exhibit high quality in sensory and nutritional attributes at the time of purchase if quality is to be maintained during longterm storage.

Sensory acceptability of NDM stored up to 54 mo has been evaluated using an 11-member trained panel

Received February 23, 2004

Accepted April 29, 2004.

Corresponding author: O. A. Pike; e-mail: oscar_pike@byu.edu.
(Driscoll et al., 1985). More recently, work has described the flavor attributes of NDM (Karagul-Yuceer et al., 2001; 2002). Hough et al. (2002) correlated trained panel flavor intensity scores with consumer acceptability of whole milk powder. However, little recent research has addressed consumer acceptability of NDM and whey powder beverages at the time of sale.

In the United States and other areas, vitamins A and D are often added to fluid milk products. Numerous studies have shown that fortification levels in fluid milk vary widely (deBoer et al., 1984; Holick et al., 1992; Jacobus et al., 1992; Blank et al., 1995; Faulkner et al., 2000; Murphy et al., 2001). The vitamin A content of 17 samples of NDM was analyzed by deBoer et al. (1984) and was found to vary widely, with 1 sample overfortified and 7 underfortified. According to the Pasteurized Milk Ordinance (FDA, 2003), manufacturers of milk products with added vitamins $\mathrm{A}$ and/or D must have the fortification levels of their products checked yearly. Fortification of NDM is optional, but if fortified, NDM must reconstitute to meet the same requirements as fluid milk, with 2000 IU/qt for vitamin A and 400 IU/ qt for vitamin $\mathrm{D}$. Thiamin (vitamin $\mathrm{B}_{1}$ ) and riboflavin (vitamin $\mathrm{B}_{2}$ ) are naturally occurring vitamins in NDM that have been quantified by several researchers (Mercurio and Tadjalli, 1979; Ford et al., 1983; Renner, 1988). An 8-oz serving of vitamin A- and D-fortified milk provides approximately $25 \%$ of the daily value (DV) of vitamin D and riboflavin, and $10 \%$ of the DV of vita$\min \mathrm{A}$.

Many researchers have reported significant improvements in the sensory quality and shelf life of milk powders stored in the absence of oxygen. Although most of this research involved whole milk powder (Coulter, 1947; Warmbier and Wolf, 1976; Tuohy, 1984; Min et al., 1989; Chan et al., 1993; Andersson and Lingnert, 1998), benefits have been found for NDM as well (Henry and Kon, 1947; Driscoll et al., 1985). Oxygen levels can be reduced by the traditional method of nitrogen flushing or by the more recently developed approach of using oxygen absorbers. Nitrogen flushing generally reduces the oxygen to 2 to $5 \%$ (Warmbier and Wolf, 1976), which is not enough to prevent oxidation (Bishov et al., 1971; Labuza, 1971; Kacyn et al., 1983). Oxygen 
absorbers generally lower oxygen to less than $1 \%$, and research has shown them to be effective in delaying oxidation in low-moisture foods (Chan et al., 1993; Ribeiro et al., 1993; Berenzon and Saguy, 1998; Emenhiser et al., 1999). To maintain low oxygen levels, packaging material must have low oxygen permeability. In the case of metal cans, they must be hermetically sealed.

Milk powders store best at low water activities (Heiss and Eichner, 1971; Labuza and Tannenbaum, 1972; Okamoto and Hayashi, 1985). Stapelfeldt et al. (1997) found that whole milk powder retained its quality best with a water activity range of 0.11 to 0.23 .

The objective of this research was to evaluate the variation in sensory and nutritional quality at the time of purchase of various brands of dried milk products packaged in No. 10 cans as a measure of their suitability for long-term storage.

\section{MATERIALS AND METHODS}

\section{Samples}

Ten brands of dried milk products (5 instant NDM, 3 regular NDM, and 2 whey beverages) packaged in No. 10 cans were obtained from retail distributors representing 7 manufacturers in 4 US states. Sample temperature during storage and distribution for retail sale was unknown. After purchase, each sample was stored at room temperature until opened. At the time of opening, a sample was removed for water activity measurement and sensory analysis. The remainder was repackaged in a 28- $\times 33$-cm foil laminate pouch (Basaw Manufacturing, Inc., North Hollywood, CA) with an oxygen absorber (Mitsubishi Gas Chemical America, Inc., New York, NY), followed by storage at $-18^{\circ} \mathrm{C}$ until nutritional analysis. Product codes indicated the brands were less than $1 \mathrm{yr}$ old, except for brand $J(2 \mathrm{yr})$ and brands $\mathrm{A}$ and $\mathrm{C}$ (unknown). The method of oxygen removal from can headspace was noted, as indicated on the package label or by the presence of an oxygen absorber. Duplicate samples of each brand (2 cans from the same batch) were evaluated.

\section{Headspace Oxygen, Can Seam, and Water Activity}

Headspace oxygen was measured using a rigid pack sampler with a $0.2-\mu \mathrm{m}$ filter and sampling wand attached to a 3500 -series headspace oxygen analyzer (Illinois Instruments, Inc., Johnsburg, IL), calibrated to atmospheric oxygen. A septum was placed on each can top, followed by puncturing with the rigid pack sampler. Once the oxygen reading stabilized, a small hole was drilled in the side of the can near the bottom to break the vacuum inside the can and to obtain the lowest, most accurate headspace oxygen reading. The instrument was set to record the lowest reading, obtained just before external air from the drilled hole increased the reading.

Can seams were evaluated using the SeamMate System (Onevision Corp., Westerville, $\mathrm{OH}$ ) to measure the following seam dimensions: thickness, width, body hook, cover hook, and overlap. Seam tightness was visually rated on a scale of 0 to $100 \%$, with $100 \%$ being completely tight. The seams were given an overall rating of good, satisfactory, or poor by an experienced evaluator.

Water activity was determined by the chilled mirror technique using an Aqualab CX-2 water activity meter (Decagon Devices, Inc., Pullman, WA).

\section{Sensory Evaluation}

Sensory analysis was conducted at the Brigham Young University Sensory Laboratory using standard procedures. Panelists were recruited from university employees and students willing to evaluate reconstituted NDM. Demographic information showed that both genders were equally represented, with approximately equal representation among age categories (20 to $59 \mathrm{yr}$ old). Samples were reconstituted to $9 \%$ solids using filtered water the day before the panel evaluation and were stored refrigerated in gallon-size milk jugs. During the panel, the jugs were kept on crushed ice. The brands were evaluated by a 54-member consumer panel, using a randomized block design. The panel was conducted in 4 sessions held over a 2-d period, with one session each morning and one each afternoon. In each session, panelists first received a set of 5 samples side by side. Then, after a several-minute-long break, panelists moved to a new booth, where they received another set of 5 samples. Approximately $30 \mathrm{~mL}$ of sample was served in plastic cups labeled with 3 -digit blinding codes. Panelists received samples through passthrough compartments in isolated booths. Each panelist tasted every sample twice, using 2 different blinding codes for the same sample. Data were collected using Compusense software (Compusense Inc., Guelph, Ontario, Canada). Panelists evaluated aroma, flavor, and overall acceptability using a 9 -point hedonic scale $(9=$ like extremely, 5 = neither like nor dislike, 1 = dislike extremely) and were instructed to take a bite of an unsalted soda cracker and a sip of filtered water to cleanse their palate between samples. The emergency acceptance of each brand was determined by asking panelists whether they would drink each sample if they were in an emergency situation where no other food was available. The intent of the question was not to predict use in an actual emergency but to determine 
the attitude of consumers toward a product marketed for use in an emergency. Panelists received monetary compensation for their time.

\section{Vitamin Determinations}

Vitamin analyses were conducted using an Agilent model 1100 HPLC (Agilent Technologies, Palo Alto, CA) equipped with a Luna $5 \mu \mathrm{C} 18(2), 150-\times 4.6-\mathrm{mm}$, reverse-phase column (Phenomenex, Inc., Torrence, CA). Determinations were carried out in duplicate in a randomized order under subdued light. All chemical standards and enzymes were obtained from Sigma-Aldrich (St. Louis, MO).

Thiamin and riboflavin. Thiamin and riboflavin were extracted using the method of Arella et al. (1996) with several modifications. The hydrochloric acid and enzymatic treatment was replaced by enzymatic treatment with $114 \mathrm{U}$ of papain, $27 \mathrm{U}$ of acid phosphatase, and $370 \mathrm{U}$ of $\alpha$-amylase (Ndaw et al., 2000). The extraction solvent consisted of sodium acetate buffer adjusted with acetic acid to a $\mathrm{pH}$ of 4.5. Also, the extracted vitamin solution was not passed through a Waters Sep Pak $\mathrm{C}_{18}$ cartridge because this step did not provide any added benefit. Thiamin was converted to thiochrome for HPLC determination.

Separations were accomplished with the following HPLC conditions: mobile phase of $0.05 \mathrm{M}$ methanolsodium acetate $(30: 70 \mathrm{vol} / \mathrm{vol}) ; 23^{\circ} \mathrm{C}$; flow rate $=1 \mathrm{~mL} /$ min; injection volume $=10 \mu \mathrm{L}$; and a fluorescence detector at an excitation wavelength of $366 \mathrm{~nm}$ and an emission wavelength of $435 \mathrm{~nm}$ for thiochrome, and at an excitation wavelength of $422 \mathrm{~nm}$ and an emission wavelength of $522 \mathrm{~nm}$ for riboflavin. Data were quantified using external calibration. Results were adjusted to account for $77 \%$ recovery of thiamin and $87 \%$ recovery of riboflavin. Percentage of recovery was determined by spiking duplicate samples with a known concentration of either thiamin or riboflavin.

Vitamin A. Vitamin A (retinol palmitate) extraction was based on the method of Gomis et al. (2000). A 5-g sample of NDM was dispersed in $30 \mathrm{~mL}$ of distilled water using an ultrasonic bath (EW-08891-21, ColeParmer, Vernon Hills, IL) for 5 min at ambient temperature, followed by addition of $30 \mathrm{~mL}$ of ethanol containing $0.025 \%$ butylated hydroxy toluene and sonication (approximately $10 \mathrm{~s}$ ) to disperse completely. The solution was quantitatively transferred to a separatory funnel, shaken for 2 min with $60 \mathrm{~mL}$ of hexane, and the hexane phase decanted. Hexane extraction was repeated on the aqueous phase 2 more times. The hexane phases were combined in a new separatory funnel and washed twice with $140 \mathrm{~mL}$ of aqueous methanol (methanol:water, 80:20). The hexane phase was collected in a

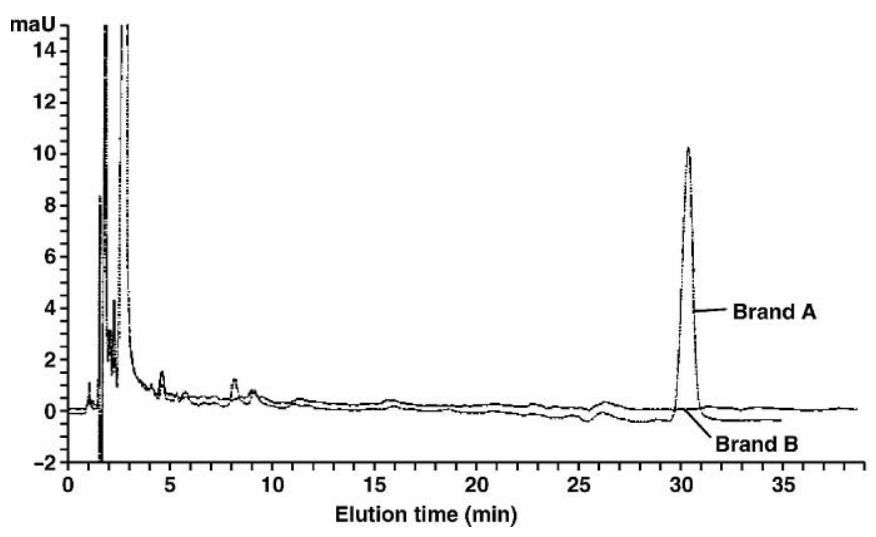

Figure 1. Representative chromatograms of samples containing (Brand A) and lacking (Brand B) vitamin A (retinol palmitate), which elutes at approximately $30 \mathrm{~min}$. Absorbance shown is at $265 \mathrm{~nm}$.

250-mL round-bottom flask and evaporated to dryness in a Rotavapor (Büchi, Flawil, Switzerland) at $40^{\circ} \mathrm{C}$ under vacuum. The residue was dissolved in $2 \mathrm{~mL}$ of methanol:methylene chloride (50:50) and quantitatively transferred to a 5 -mL volumetric flask and brought to volume with the same solvent. The solution was filtered through a syringe fitted with a polytetrafluoroethylene $0.45-\mu \mathrm{m}$ filter into an autosampler vial for chromatographic determination of vitamin A.

The HPLC separation was accomplished under the following conditions: gradient mobile phase of $18 \%$ acetonitrile, $70.2 \%$ methanol, $7.8 \%$ tetrahydrofuran, and $4 \%$ water for $18 \mathrm{~min}$, and then changed to $25 \%$ acetonitrile and $75 \%$ methanol:THF (90:10) over the next 7 min, and continued for an additional $15 \mathrm{~min}$ to complete the run; $23^{\circ} \mathrm{C}$; flow rate $=1 \mathrm{~mL} / \mathrm{min}$; injection volume = $30 \mu \mathrm{L}$; and a UV diode array detector at a wavelength of $265 \mathrm{~nm}$ for vitamin A and $500 \mathrm{~nm}$ as reference. The Gomis et al. (2000) method is designed to analyze multiple fat-soluble vitamins simultaneously, and thus uses $265 \mathrm{~nm}$, the UV maximum for cholecalciferol (instead of $325 \mathrm{~nm}$, the UV maximum for vitamin A). Figure 1 shows chromatograms of representative samples, one with vitamin A present and the other with no detectable vitamin A. To determine if other forms of vitamin A might have been present in each sample, data from the diode array detector obtained at $325 \mathrm{~nm}$ were evaluated and no other major peaks were found. If present, the extraction procedure would have retrieved retinol acetate (the other form of vitamin A commonly used to fortify milk besides retinol palmitate), which would have eluted at approximately 4 to $5 \mathrm{~min}$. Analysis of small peaks eluting in this time range indicated that none of the peaks matched the UV spectrum of retinol acetate. 


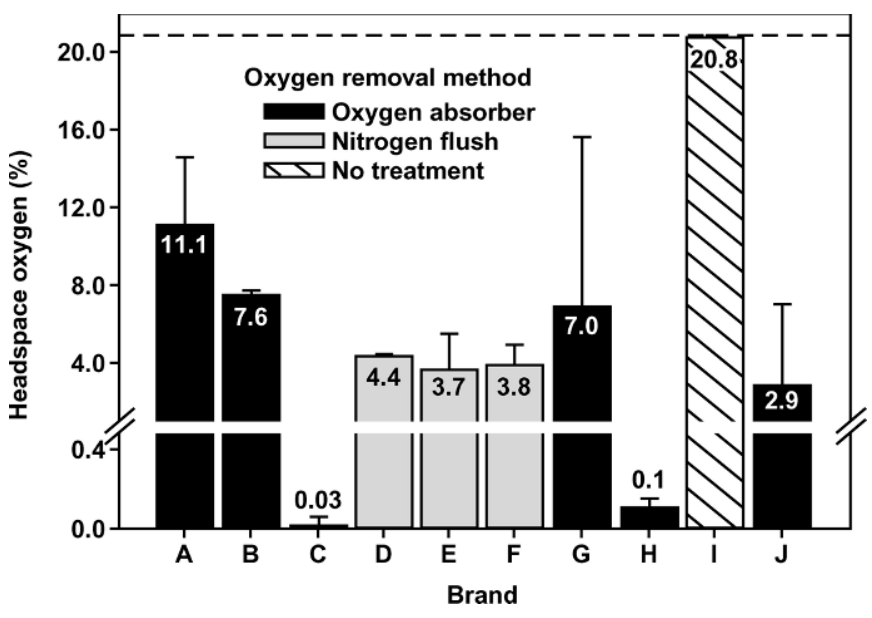

Figure 2. Headspace oxygen in various brands of dried milk products. Brands A to E are instant NDM, $\mathrm{F}$ to $\mathrm{H}$ are regular NDM, and $\mathrm{I}$ to $\mathrm{J}$ are dried whey beverages. Error bars represent standard deviation.

Data were quantified using external calibration. Results were adjusted to account for $94 \%$ recovery of vita$\min \mathrm{A}$, which was determined by spiking duplicate samples with a known concentration of vitamin A.

\section{Data Analysis}

Data were analyzed for significance using SAS software (Version 8.02, SAS Inst., Inc., Cary, NC). Sensory data were subjected to a mixed model repeated measures ANOVA (PROC MIXED) and Duncan's multiple range test was used to determine significant differences between sample means. The model tested for the difference between brands and included multiple cans within brands. Water activity and vitamin data were analyzed using PROC GLM with Duncan's multiple range test. Significant differences were defined as $P<0.05$.

\section{RESULTS AND DISCUSSION}

\section{Headspace Oxygen, Can Seam, and Water Activity}

Headspace oxygen (Figure 2) varied widely from brand to brand. Factors that possibly influence headspace oxygen include efficacy of oxygen removal method, the time since oxygen removal (since a slow leak would allow a gradual increase in oxygen), the presence of a compound in the seam, and can seam quality (Figure 3). Brands A, B, and G had higher than expected oxygen levels as well as poor seams. Brand $J$ contained an oxygen absorber and had a satisfactory seam, but the oxygen level was not low. It is possible that the oxygen absorber was partially expended prior to canning and did not have enough absorbing capacity

\begin{tabular}{|c|c|c|c|c|c|}
\hline Brand & A & B & C & D & E \\
\hline \multicolumn{6}{|l|}{ Seam cross section } \\
\hline Tightness rating & $35 \%$ & $100 \%$ & $55 \%$ & $95 \%$ & $70 \%$ \\
\hline Overall seam rating & Poor & Poor & Satisfactory & Good & Good \\
\hline Brand & $\mathbf{F}$ & G & H & I & $J$ \\
\hline \multicolumn{6}{|l|}{ Seam cross section } \\
\hline Tightness rating & $85 \%$ & $100 \%$ & $95 \%$ & $100 \%$ & $60 \%$ \\
\hline Overall seam rating & Good & Poor & Satisfactory & Poor & Satisfactory \\
\hline
\end{tabular}

Figure 3. Representative can seam cross section, tightness rating, and overall seam rating for each brand. Brands A to E are instant NDM, F to $\mathrm{H}$ are regular NDM, and I to $\mathrm{J}$ are dried whey beverages.

left to sufficiently reduce the headspace oxygen within the can. For the brands with satisfactory or good seams, oxygen absorbers reduced the headspace oxygen better than nitrogen flushing. Eight of the brands had $>2 \%$ headspace oxygen, indicating that oxidation reactions would not be inhibited (Kacyn et al., 1983).

The water activity of the brands ranged from 0.14 to 0.28 (Figure 4), but all values were in a typical range, corresponding to 3 to $5 \%$ moisture (Walstra et al., 1999). Research (Labuza et al., 1970; Stapelfeldt et al., 1997) suggests that the deterioration reactions of lipid oxidation and Maillard browning in milk powder are limited in this water activity range. According to Stapelfeldt et al. (1997), the ideal range for water activity for whole milk powder is 0.11 to 0.23 . All samples fell within this range except for brands $\mathrm{B}$ and $\mathrm{J}$. It is possible that a slightly higher water activity in these 2 brands may have had some influence on sensory quality.

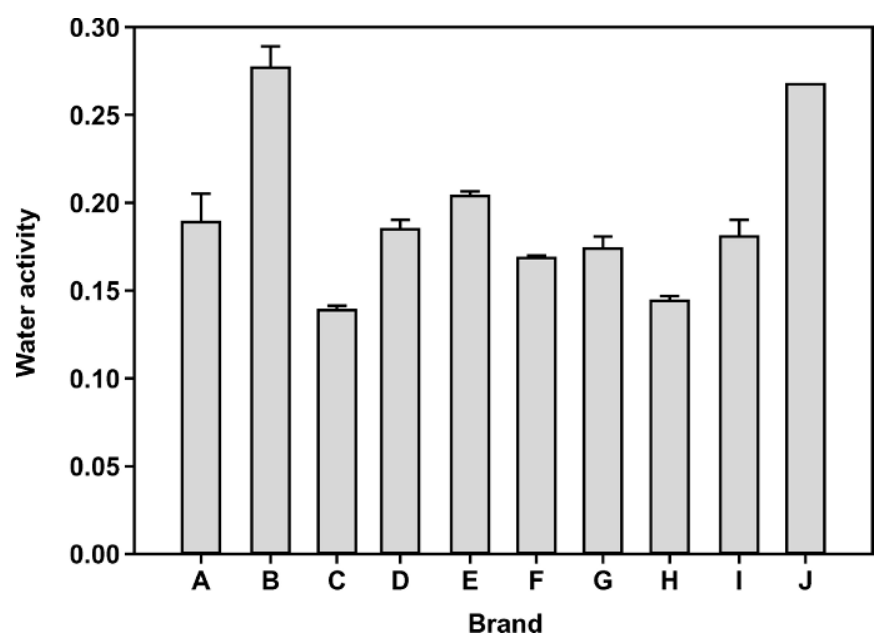

Figure 4. Water activity of various brands of dried milk products. Brands $\mathrm{A}$ to $\mathrm{E}$ are instant NDM, $\mathrm{F}$ to $\mathrm{H}$ are regular NDM, and I to $\mathrm{J}$ are dried whey beverages. Error bars represent standard deviation. 
Table 1. Mean values of hedonic scores (9-point scale) for aroma, flavor, and overall acceptability of dried milk products.

\begin{tabular}{lllll}
\hline Brand & Product type & Aroma & Flavor & Overall \\
\hline A & Instant NDM & $5.47^{\mathrm{a}}$ & $5.61^{\mathrm{a}}$ & $5.55^{\mathrm{b}}$ \\
$\mathrm{B}$ & Instant NDM & $5.14^{\mathrm{bc}}$ & $4.46^{\mathrm{de}}$ & $4.56^{\mathrm{de}}$ \\
$\mathrm{C}$ & Instant NDM & $5.39^{\mathrm{ab}}$ & $5.54^{\mathrm{b}}$ & $5.60^{\mathrm{ab}}$ \\
$\mathrm{D}$ & Instant NDM & $5.02^{\mathrm{c}}$ & $4.19^{\mathrm{e}}$ & $4.25^{\mathrm{e}}$ \\
$\mathrm{E}$ & Instant NDM & $5.22^{\mathrm{abc}}$ & $4.46^{\mathrm{de}}$ & $4.60^{\mathrm{de}}$ \\
$\mathrm{F}$ & Regular NDM & $5.26^{\mathrm{abc}}$ & $5.13^{\mathrm{bc}}$ & $5.08^{\mathrm{c}}$ \\
$\mathrm{G}$ & Regular NDM & $5.52^{\mathrm{a}}$ & $6.02^{\mathrm{a}}$ & $6.03^{\mathrm{a}}$ \\
$\mathrm{H}$ & Regular NDM & $5.05^{\mathrm{c}}$ & $4.13^{\mathrm{e}}$ & $4.20^{\mathrm{e}}$ \\
$\mathrm{I}$ & Whey Beverage & $5.26^{\mathrm{abc}}$ & $4.77^{\mathrm{cd}}$ & $4.79^{\mathrm{cd}}$ \\
$\mathrm{J}$ & Whey Beverage & $5.24^{\mathrm{abc}}$ & $4.37^{\mathrm{de}}$ & $4.43^{\mathrm{de}}$ \\
\hline
\end{tabular}

a,b,c,d,e Means within columns followed by the same superscript are not significantly different $(P>0.05)$.

\section{Sensory Evaluation}

There were significant differences between brands in mean hedonic scores for sensory attributes (Table 1). Mean hedonic scores for aroma ranged from 5.0 to 5.5, corresponding to neither like nor dislike. It should be noted that statistically significant differences for aroma are not necessarily of practical significance. Flavor scores ranged from 4.1 (dislike a little) to 6.0 (like a little). Overall acceptability scores ranged from 4.2 to 6.0. Scores for aroma and flavor generally corresponded with overall acceptability. There was no correlation between hedonic scores and headspace oxygen, indicating that the variation in sensory scores was due to other factors, such as initial fluid milk quality, processing conditions, and storage temperature. Storage time may not have been long enough for headspace oxygen to affect overall acceptability. This agrees with the research of Norseth (1986), who did not find atmosphere to have a significant effect on the sensory acceptability of NDM after $3 \mathrm{yr}$ of storage. However, the brand that scored highest in overall acceptability had an average headspace oxygen of $7 \%$ and poor can seams, calling into question the ability of the packaging to maintain product quality over an extended storage time. Brand $\mathrm{H}$ was spray-dried 6 mo before it was packaged in a No. 10 can, and the flavor may have deteriorated during that time, depending on its storage conditions. Brand $\mathrm{J}$ may have scored lower because it was older than the other brands.

It is interesting to note the differences in mean hedonic scores between the 3 categories of dried milk products. Regular NDM brands had a mean flavor score significantly higher than the instant NDM brands (5.09 and 4.85 , respectively), but there was no significant difference in mean overall acceptability scores (5.11 and 4.91 , respectively). The whey beverages scored significantly lower than the regular or instant NDM in flavor (4.57) and overall acceptability (4.61). There were no

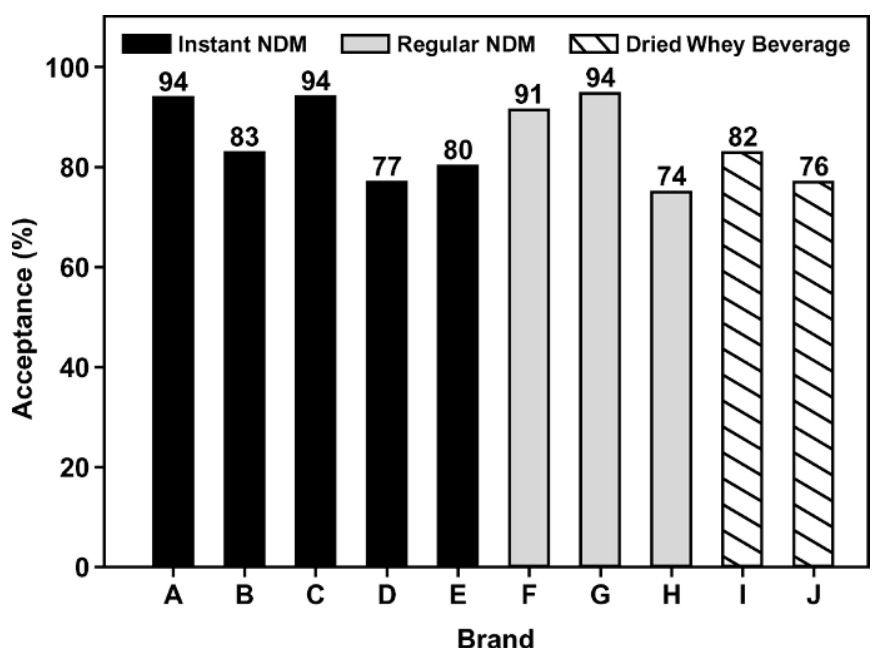

Figure 5. Percentage of panelists who would drink each brand of instant NDM, regular NDM, and dried whey beverage in an emergency situation.

significant differences in sensory scores for aroma between the categories.

Acceptance for emergency use (Figure 5) ranged from 74 to $94 \%$. This is further evidence of the variation in the sensory quality of various brands of dried milk products marketed for emergency use, even before the consumer has stored the product.

\section{Vitamin Content}

Thiamin content (Figure 6) was not significantly different between brands, with the exception of brand J,

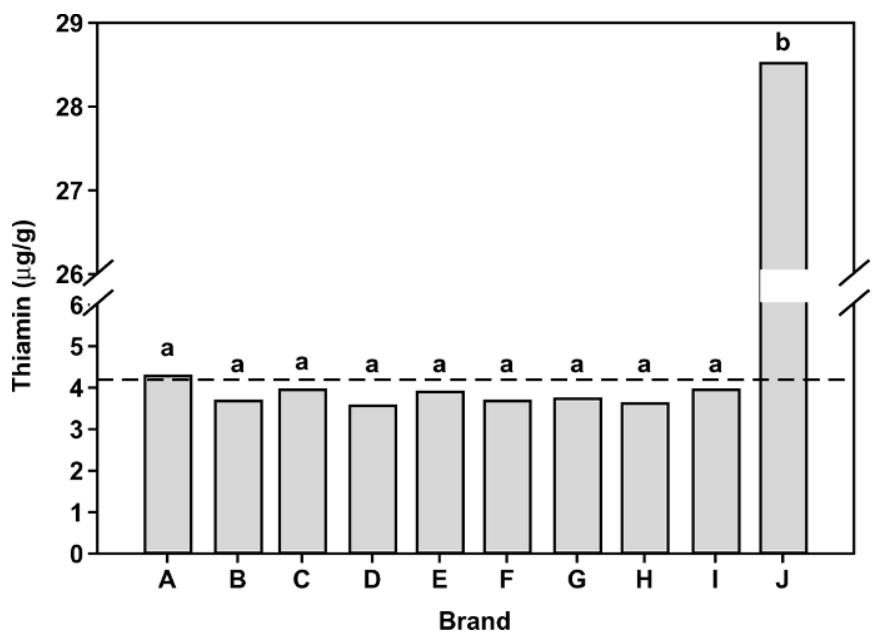

Figure 6. Thiamin (vitamin B1) content of dried milk products. Brands $\mathrm{A}$ to $\mathrm{E}$ are instant NDM, $\mathrm{F}$ to $\mathrm{H}$ are regular NDM, and I to $\mathrm{J}$ are dried whey beverages. Dashed line represents typical thiamin level in instant NDM $(4.13 \mu \mathrm{g} / \mathrm{g})$ from the USDA National Nutrient Database for Standard Reference (thiamin content of regular NDM is $4.15 \mu \mathrm{g} / \mathrm{g})$. Like superscripts are not significantly different $(P>0.05)$. 


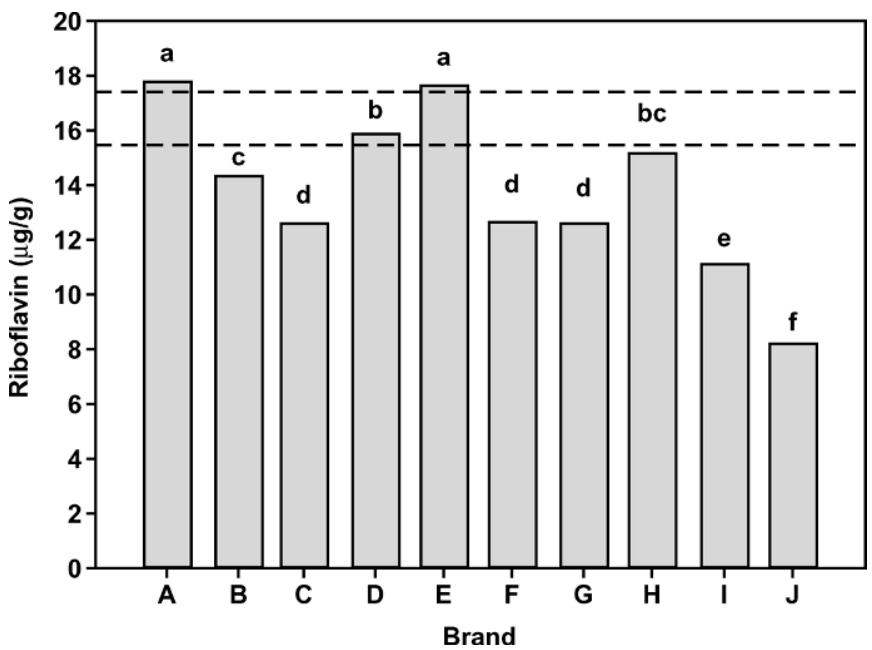

Figure 7. Riboflavin (vitamin $\mathrm{B}_{2}$ ) content of dried milk products. Brands $\mathrm{A}$ to $\mathrm{E}$ are instant NDM, $\mathrm{F}$ to $\mathrm{H}$ are regular NDM, and I to $\mathrm{J}$ are dried whey beverages. Dashed lines represent typical riboflavin level in instant $(17.44 \mu \mathrm{g} / \mathrm{g})$ and regular $(15.50 \mu \mathrm{g} / \mathrm{g}) \mathrm{NDM}$ from the USDA National Nutrient Database for Standard Reference. Like superscripts are not significantly different $(P>0.05)$.

which had a high content due to fortification. According to the label, there should have been $17.9 \mu \mathrm{g} / \mathrm{g}(25 \% \mathrm{DV})$, but it was found to have an average of $28.5 \mu \mathrm{g} / \mathrm{g}(40 \%$ DV). The other brands were closer to the $4.13 \mu \mathrm{g} / \mathrm{g}(6 \%$ DV) thiamin content of instant NDM given in the USDA National Nutrient Database for Standard Reference (USDA, 2003).

Riboflavin content (Figure 7) varied between the brands, ranging from 7.2 to $17.9 \mu \mathrm{g} / \mathrm{g}$ (9 to $24 \% \mathrm{DV}$ ), with only 2 brands reaching the USDA National Nutrient Database for Standard Reference (USDA, 2003) value of $17.44 \mu \mathrm{g} / \mathrm{g}(24 \% \mathrm{DV})$. It is possible that the low values for riboflavin were due to light sensitivity of the vitamin and differences in processing conditions where dry powder may be exposed to light before packaging.

Vitamin A ranged from none detected to $3600 \mathrm{IU} / \mathrm{qt}$ (Figure 8), with measurable amounts in only 4 of the brands. Those brands containing vitamin A were at or near the target fortification level of 2000 to $3000 \mathrm{IU} /$ qt. One of the brands showed a large variation between cans, indicating that the fortification level was not consistent. It would be expected that over time, the vitamin A would best be preserved in brands with low amounts of oxygen in the headspace, inasmuch as this vitamin is susceptible to oxidation. However, there was no relationship between headspace oxygen and vitamin A in these relatively fresh samples of various brands.

\section{Product Labeling}

Some of the product labels contained gross errors. All of the brand labels claimed vitamin A fortification, yet

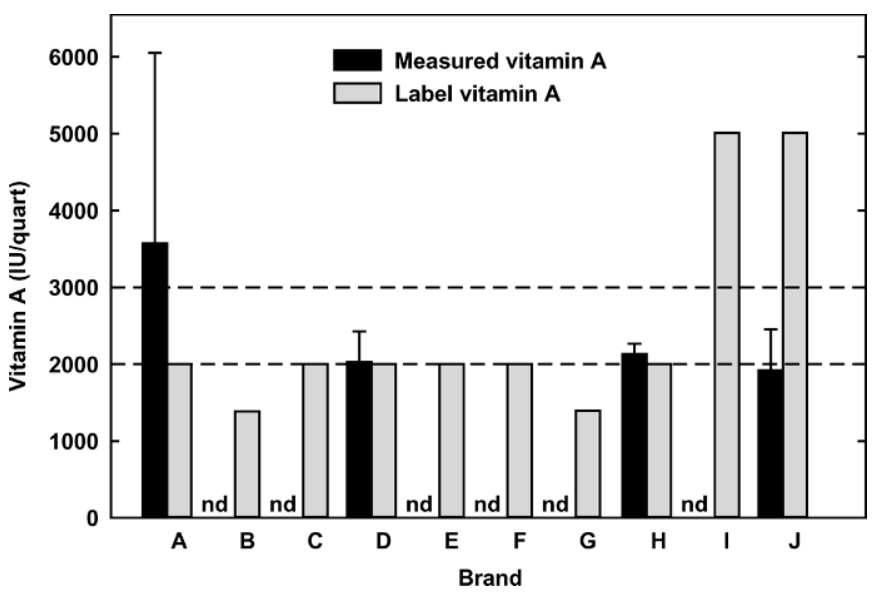

Figure 8. Comparison of label and measured values of vitamin A (retinol palmitate) in dried milk products. Brands A to E are instant nonfat dry milk (NDM), $\mathrm{F}$ to $\mathrm{H}$ are regular NDM, and I to $\mathrm{J}$ are dried whey beverages. Amounts given in IU per quart, reconstituted according to label directions. Error bars represent standard deviation. nd $=$ none detected. Dashed lines represent acceptable fortification range for milk of 2000 to 3000 IU/quart, set by US regulations.

vitamin A was detected only in brands $\mathrm{A}, \mathrm{D}, \mathrm{H}$, and $\mathrm{J}$. The label of brand $\mathrm{B}$ gave improper mixing instructions, reconstituting to $18 \%$ solids rather than the typical $9 \%$. The label for brand $\mathrm{H}$ was inconsistent, with mixing directions reconstituting to $9 \%$ solids but a nutrition facts label corresponding to $13 \%$ solids. The nutrition facts label for brand F listed 25\% DV for iron, but milk contains an insignificant level of iron $(<1 \%$ DV). It appears that companies that purchase NDM in bulk quantities and further repackage it in No. 10 cans need to verify label information, including ingredients, nutritional content, and mixing instructions.

\section{CONCLUSIONS}

There is wide variation in sensory and nutritional quality of dried milk products packaged in No. 10 cans, as purchased from retail distributors. Good manufacturing practices must be observed to optimize product quality, giving careful attention to can seam quality, product labeling, and vitamin fortification levels. Companies should consider the competitive advantage of having an outside laboratory certify their products for quality control purposes. Consumers should look for companies that guarantee the quality of their products and would be well advised to evaluate the flavor of several brands of dried milk products prior to purchasing large quantities.

\section{ACKNOWLEDGMENTS}

The authors appreciate the funding for this research provided by I. Fulton and the contributions of the fol- 
lowing individuals: D. Rose, S. Bevan, A. Ellsworth, T. Oesterle, M. Halling, M. McEwan, N. Van Noy, L. Jefferies, and D. Eggett.

\section{REFERENCES}

Andersson, K., and H. Lingnert. 1998. Influence of oxygen concentration on the flavour and chemical stability of cream powder. Food Sci. Technol./Lebensm-Wiss. Technol. 31:245-251.

Arella, F., S. Lahely, J. B. Bourguignon, and C. Hasselmann. 1996. Liquid chromatographic determination of vitamins B-1 and B-2 in foods. A collaborative study. Food Chem. 56:81-86.

Berenzon, S., and I. S. Saguy. 1998. Oxygen absorbers for extension of crackers shelf-life. Food Sci. Technol./Lebensm. Wiss Technol. $31: 1-5$.

Bishov, S., A. Henick, J. Giffee, I. Nii, P. Prell, and M. Wolf. 1971. Quality and stability of some freeze-dried foods in 'zero' oxygen headspace. J. Food Sci. 36:532-535.

Blank, S., K. S. Scanlon, T. H. Sinks, S. Lett, and H. Falk. 1995. An outbreak of hypervitaminosis-D associated with the overfortification of milk from a home-delivery dairy. Am. J. Public Health. 85:656-659.

Chan, S. H., J. I. Gray, E. A. Gomaa, B. R. Harte, P. M. Kelly, and D. J. Buckley. 1993. Cholesterol oxidation in whole milk powders as influenced by processing and packaging. Food Chem. 47:321-328.

Coulter, S. T. 1947. The keeping quality of dry whole milk spray dried in an atmosphere of an inert gas. J. Dairy Sci. 30:995-1002.

DHS (U.S. Department of Homeland Security). 2003. Emergencies \& Disasters. Washington, DC. Available: http://www.dhs.gov/ dhspublic/theme_home2.jsp. Accessed Aug. 5, 2003.

deBoer, M., L. deMan, and J. deMan. 1984. Effect of time and storage conditions on vitamin A in instantized nonfat dry milk. J. Dairy Sci. 67:2188-2191.

Driscoll, N., C. Brennand, and D. Hendricks. 1985. Sensory quality of nonfat dry milk after long-term storage. J. Dairy Sci. 68:1931-1935.

Emenhiser, C., R. Watkins, N. Simunovic, N. Solomons, J. Bulux, J. Barrows, and S. Schwartz. 1999. Packaging preservation of beta carotene in sweet potato flakes using flexible film and an oxygen absorber. J. Food Qual. 22:63-73.

Faulkner, H., A. Hussein, M. Foran, and L. Szijarto. 2000. A survey of vitamin A and D contents of fortified fluid milk in Ontario. J. Dairy Sci. 83:1210-1216.

FDA. 2003. Grade "A" pasteurized milk ordinance-2001 revision. Washington, DC. Online. Available: http://www.cfsan.fda.gov/ ear/pmo01-2.html. Accessed June 11, 2003.

Ford, J., R. Hurrell, and P. Fino. 1983. Storage of milk powders under adverse conditions 2 . Influence on the content of water-soluble vitamins. Br. J. Nutr. 49:355-364.

Gomis, D. B., M. P. Fernandez, and M. D. G. Alvarez. 2000. Simultaneous determination of fat-soluble vitamins and provitamins in milk by microcolumn liquid chromatography. J. Chromat. A. 891:109-114.

Heiss, R., and E. Eichner. 1971. Moisture content and shelf life. Food Manuf. 46:37-38, 41-42.

Henry, K. M., and S. Kon. 1947. Deterioration on storage of dried skim milk. J. Dairy Res. 15:292-363.

Holick, M. F., Q. Shao, W. W. Liu, and T. C. Chen. 1992. The vitaminD content of fortified milk and infant formula. N. Engl. J. Med. $326: 1178-1181$.
Hough, G., R. H. Sanchez, G. G. de Pablo, R. G. Sanchez, S. C. Villaplana, A. M. Gimenez, and A. Gambaro. 2002. Consumer acceptability versus trained sensory panel scores of powdered milk shelf-life defects. J. Dairy Sci. 85:2075-2080.

Jacobus, C. H., M. F. Holick, Q. Shao, T. C. Chen, I. A. Holm, J. M. Kolodny, G. E. Fuleihan, and E. W. Seely. 1992. Hypervitaminosis-D associated with drinking milk. N. Engl. J. Med. 326:1173-1177.

Kacyn, L., I. Saguy, and M. Karel. 1983. Kinetics of oxidation of dehydrated food at low oxygen pressures. J. Food Process. Preserv. 7:161-178.

Karagul-Yuceer, Y., K. R. Cadwallader, and M. Drake. 2002. Volatile flavor components of stored nonfat dry milk. J. Agric. Food Chem. 50:305-312.

Karagul-Yuceer, Y., M. Drake, and K. R. Cadwallader. 2001. Aromaactive components of nonfat dry milk. J. Agric. Food Chem. 49:2948-2953.

Labuza, T. P. 1971. Kinetics of lipid oxidation in foods. CRC Crit. Rev. Food Technol. 2:355-405.

Labuza, T. P., and S. R. Tannenbaum. 1972. Nutrient losses during drying and storage of dehydrated foods. CRC Crit. Rev. Food Technol. 3:217-240.

Labuza, T. P., S. R. Tannenbaum, and M. Karel. 1970. Water content and stability of low-moisture and intermediate-moisture foods. Food Technol. 24:35-42.

Mercurio, K. C., and V. A. Tadjalli. 1979. Nutritive and sensory evaluation of 20-year-old nonfat dry milk. J. Dairy Sci. 62:633636,1245

Min, D., S. Lee, and J. Lindamood. 1989. Effect of packaging conditions on the flavor stability of dry whole milk. J. Food Sci. 54:1222-1224.

Murphy, S. C., L. J. Whited, L. C. Rosenberry, B. H. Hammond, D. K. Bandler, and K. J. Boor. 2001. Fluid milk vitamin fortification compliance in New York state. J. Dairy Sci. 84:2813-2820.

Ndaw, S., M. Bergaentzle, and D. Aoudé-Werner. 2000. Extraction procedures for the liquid chromatographic determination of thiamin, riboflavin and vitamin $B_{6}$ in foodstuffs. Food Chem. 71:129-138.

Norseth, A. L. 1986. Storage of low-moisture foods: Effect of storage temperature, time and oxygen level on consumer acceptability and nutrient content. M.S. Thesis. Brigham Young Univ., Provo, Utah.

Okamoto, M., and R. Hayashi. 1985. Chemical and nutritional changes of milk powder proteins under various water activities. Agric. Biol. Chem. 49:1683-1687.

Renner, E. 1988. Storage stability and some nutritional aspects of milk powders and ultra high temperature products at high ambient temperatures. J. Dairy Res. 55:125-142.

Ribeiro, M. A. A., M. A. B. Regitanodarce, U. A. Lima, and M. C. S. Nogueira. 1993. Storage of canned shelled brazil nuts (Bertholletia excelsa) - effects on the quality. Acta Aliment. 22:295-303.

Stapelfeldt, H., B. Nielsen, and L. Skibsted. 1997. Effect of heat treatment, water activity, and storage temperature, on the oxidative stability of whole milk powder. Int. Dairy J. 7:331-339.

Tuohy, J. 1984. Developments in the packaging of whole milk powder. Farm Food Res. 15:7-9.

USDA. 2003. USDA National Nutrient Database for Standard Reference, Release 15. Washington, DC. Available: http://www.nal. usda.gov/fnic/cgi-bin/nut search.pl. Accessed June 11, 2003.

Walstra, P., T. Geurts, A. Noomen, A. Jellema, and M. van Boekel. Eds. 1999. Page 269 in Dairy technology: Principles of milk properties and processes. Marcel Dekker, New York.

Warmbier, H., and M. Wolf. 1976. A pouch for oxygen-sensitive products. Mod. Pack. 49:38-41. 